\title{
Unravelling the characteristics of Al-alloy corrosion at the atomic to nanometre scale by transmission electron microscopy
}

\author{
Shravan K. Kairy,", and Nick Birbilis ${ }^{2}$ \\ ${ }^{1}$ Department of Materials Science and Engineering, Monash University, Clayton, Victoria, 3800, Australia. \\ ${ }^{2}$ College of Engineering and Computer Science, The Australian National University, Acton, ACT, 2601, Australia.
}

\begin{abstract}
The localised corrosion associated with $\mathrm{Mg}_{2} \mathrm{Si}$ in the Al-matrix of an Al-Mg-Si alloy was studied in $0.1 \mathrm{M} \mathrm{NaCl}$ at $\mathrm{pH} 6$ by quasi in-situ transmission electron microscopy. Herein, physical imaging of corrosion at the atomic to nanometre scale was performed. Phase transformation and subsequent chemical composition variations associated with the localised corrosion of $\mathrm{Mg}_{2} \mathrm{Si}$ were studied. It was observed that corrosion initiated upon $\mathrm{Mg}_{2} \mathrm{Si}$, often preferentially at the interface with the Al-matrix, and propagated until $\mathrm{Mg}_{2} \mathrm{Si}$ was completely dealloyed by Mg-dissolution, resulting in an amorphous SiO-rich phase remnant. The SiO-rich remnant became electrochemically inert and did not initiate corrosion in the Almatrix. This study provides a clear understanding on the localised corrosion of Al-alloys associated with $\mathrm{Mg}_{2} \mathrm{Si}$. In addition, the methodology followed in this study can also be applied to understand the role of precipitates and second phase particles in the localised corrosion of Al-alloy systems.
\end{abstract}

\section{Introduction}

Precipitation hardenable aluminium $(\mathrm{Al})$ alloys such as 6xxx (Al-Mg-Si-(Cu)), 2xxx (Al-Cu-(Mg)) and 7xxx (Al$\mathrm{Zn}-\mathrm{Mg}-(\mathrm{Cu}))$ are strengthened by alloying additions and heat treatment processes that cause evolution of nanoscale precipitates in the Al-matrix [1-2]. However, such microstructures, which are intentionally generated for increasing strength, notably deteriorate the localised corrosion resistance of the alloys [1-5]. Nanoscale precipitates exhibit electrochemical characteristics that are different from the Al-matrix, resulting in the selective dissolution of precipitates or the surrounding Al-matrix, leading to pitting and/or intergranular corrosion (IGC) [37]. The extent of localised corrosion experienced by different Al-alloys is dependent on the type (and composition) of precipitates within the alloy, and therefore, a definitive understanding of the role of specific nanoscale precipitates in the localised corrosion of Alalloys is essential. Transmission electron microscopy (TEM) has the ability to image corrosion up to nanometre to atomic scale, and simultaneously record any chemical variations and phase transformations that occur during the corrosion process via energy dispersive X-ray spectroscopy (EDXS) and electron diffraction, respectively. Herein, as an example, the role of $\mathrm{Mg}_{2} \mathrm{Si}$ in the localised corrosion of Al-alloys was studied using a quasi in-situ TEM technique [8].

\footnotetext{
* Corresponding author: shravan.kairy@monash.edu
}

Nanoscale $\mathrm{Mg}_{2} \mathrm{Si}$ precipitates play a dominant role in increasing the strength of $\mathrm{Cu}$-free 6xxx Al-alloys [1-2, 912]. However, these alloys suffer IGC with the evolution of $\mathrm{Mg}_{2} \mathrm{Si}$ precipitates along grain boundaries during ageing [13-17]. Electrochemical tests were performed upon synthesised $\mathrm{Mg}_{2} \mathrm{Si}$ bulk specimens, and also through the electrochemical microcell technique on microscale $\mathrm{Mg}_{2} \mathrm{Si}$ particles in the Al-matrix [18-19]. Based on the tests, it was identified that $\mathrm{Mg}_{2} \mathrm{Si}$ was less noble than the Al-matrix in neutral and acidic $\mathrm{NaCl}$ [18-19]. A consensus on the dealloying of $\mathrm{Mg}_{2} \mathrm{Si}$ by Mg-dissolution in acidic and neutral $\mathrm{NaCl}$ exist [8, 18-39]. However, a consensus on the role of dealloyed $\mathrm{Mg}_{2} \mathrm{Si}$ in the localised corrosion do not exist. Of the limited studies on $\mathrm{Mg}_{2} \mathrm{Si}$ exist to date, a few studies reported that following complete dealloying of $\mathrm{Mg}_{2} \mathrm{Si}$ by $\mathrm{Mg}$ dissolution, the Sirich remnants were enriched in $\mathrm{O}$ and did not take part in the corrosion process [21-22, 30-33]. In contrast, ambivalent electrochemical characteristics of $\mathrm{Mg}_{2} \mathrm{Si}$ in Al-alloys was also reported [34-38]. It was observed that following initial dealloying, $\mathrm{MgSi}$ remnants became cathodic, more noble than the Al-matrix, resulting in the dissolution of the Al-matrix [34-38].

Herein, the localised corrosion associated with an $\mathrm{Mg}_{2} \mathrm{Si}$ particle in the Al-matrix of a $6 \times x x$ Al-alloy in 0.1 $\mathrm{M} \mathrm{NaCl}$ at $\mathrm{pH} 6$ was studied at nanometre to atomic scale by a quasi in-situ TEM technique. 


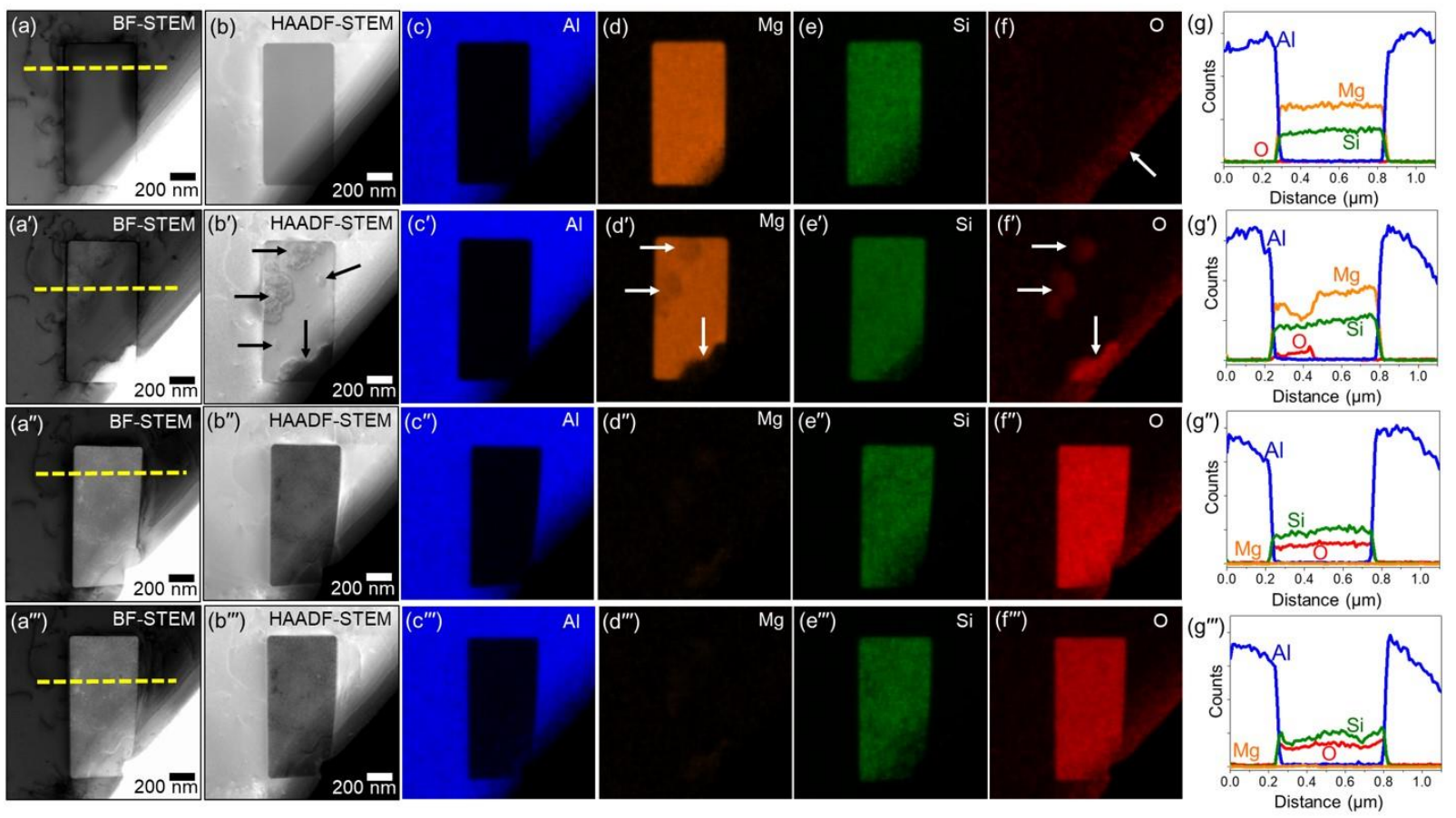

Fig. 1. BF- and HAADF-STEM images of an $\mathrm{Mg}_{2} \mathrm{Si}$ particle in the Al-matrix of an Al-0.8Mg-0.6Si alloy, (a, b) prior to immersion, and following immersion in $0.1 \mathrm{M} \mathrm{NaCl}$ for $\left(\mathrm{a}^{\prime}, \mathrm{b}^{\prime}\right) 3 \mathrm{~s},\left(\mathrm{a}^{\prime \prime}, \mathrm{b}^{\prime \prime}\right) 30 \mathrm{~s}$ and $\left(\mathrm{a}^{\prime \prime \prime}, \mathrm{b}^{\prime \prime \prime}\right) 30 \mathrm{~min}$. Quantified EDXS maps in (c-f), ( $\left.\mathrm{c}^{\prime}-\mathrm{f}^{\prime}\right)$, $\left(\mathrm{c}^{\prime \prime}-\mathrm{f}^{\prime \prime}\right)$ and $\left(\mathrm{c}^{\prime \prime \prime}-\mathrm{f}^{\prime \prime}\right)$ correspond to $(\mathrm{a}, \mathrm{b}),\left(\mathrm{a}^{\prime}, \mathrm{b}^{\prime}\right),\left(\mathrm{a}^{\prime \prime}, \mathrm{b}^{\prime \prime}\right)$ and $\left(\mathrm{a}^{\prime \prime \prime}, \mathrm{b}^{\prime \prime \prime}\right)$, respectively. EDXS composition analysis along dashed lines in $\left(\mathrm{a}-\mathrm{a}^{\prime \prime \prime}\right)$ are provided in $\left(\mathrm{g}-\mathrm{g}^{\prime \prime \prime}\right)$, respectively. The arrow in (f) shows $\mathrm{O}$ enrichment in the Al-matrix at the edge of the TEM foil. Arrows in $\left(\mathrm{b}^{\prime}\right)$ point to corroded sites within the $\mathrm{Mg}_{2} \mathrm{Si}$ particle, and the $\mathrm{Mg}$ depletion and $\mathrm{O}$ enrichment at the corresponding sites are indicated by arrows in $\left(\mathrm{d}^{\prime}\right)$ and $\left(\mathrm{f}^{\prime}\right)$, respectively.

\section{Experimental}

\subsection{Material}

A 6xxx Al-alloy, Al-0.8Mg-0.6Si (\% in mass fraction) was chosen for the present study. Alloy specimens were thermally treated in a PerkinElmer Pyris Diamond differential scanning calorimeter. The heat treatment involved solutionising at $540^{\circ} \mathrm{C}$ for $20 \mathrm{~min}$ and then cooling at $0.1 \mathrm{~K} / \mathrm{s}$ to a room temperature. The detailed procedure was described elsewhere [40]. Such a thermal treatment resulted in the growth of monocrystalline $\mathrm{Mg}_{2} \mathrm{Si}$ particles in the Al-matrix.

\subsection{Transmission electron microscopy}

A quasi in-situ TEM technique was applied to investigate the role of $\mathrm{Mg}_{2} \mathrm{Si}$ in the localised corrosion of Al-alloys. Microstructural and microchemistry variations of an $\mathrm{Mg}_{2} \mathrm{Si}$ particle in the Al-matrix were studied prior to immersion of a TEM specimen in $0.1 \mathrm{M} \mathrm{NaCl}$ at $\mathrm{pH}$, and following immersion for $3 \mathrm{~s}, 30 \mathrm{~s}$ and $30 \mathrm{~min}$. Specimens were subsequently cleaned in ethanol following immersion in $\mathrm{NaCl}$, and vacuum dried prior to TEM observation.

A Gatan 691 precision ion polishing system was used for the TEM specimen preparation, which involved thinning of $3 \mathrm{~mm}$ diameter disc at $-80^{\circ} \mathrm{C}$. In addition, a Gatan Solarus 950 advanced plasma system was used for plasma cleaning of TEM specimens for 2-10 min using an
Ar and $\mathrm{O}_{2}$ gas mixture, immediately prior to the specimen loading into a TEM. An FEI Tecnai $\mathrm{G}^{2}$ F20 S-TWIN FEG TEM at $200 \mathrm{kV}$ was operated in Scanning TEM (STEM) and TEM modes. In the STEM mode, bright field (BF) as well as high angle angular dark field (HAADF) images were collected. For microchemistry analysis, EDXS was performed with an X-flash X-ray detector using a Bruker Quantax 400. The collected EDXS hypermap data was then quantified by Cliff-Lorimer method using a Bruker Esprit1.9 X-ray software. In the TEM mode, electron diffraction to obtain selected area diffraction patterns (SADPs) and atomic resolution imaging were performed to study phase transformation associated with localised corrosion.

\section{Results and Discussion}

Scanning TEM imaging of an $\mathrm{Mg}_{2} \mathrm{Si}$ particle in the Almatrix and the corresponding chemical composition variations prior to and following a period of corrosion are provided in Fig. 1. In the pristine condition, i.e. prior to immersion in $0.1 \mathrm{M} \mathrm{NaCl}$, a submicrometre sized $\mathrm{Mg}_{2} \mathrm{Si}$ particle in the Al-matrix can be seen in Fig. $1(\mathrm{a}, \mathrm{b})$. The quantified chemical composition of the $\mathrm{Mg}_{2} \mathrm{Si}$ particle and the surrounding Al-matrix as shown in Fig. 1 (c-f), revealed that the particle contained $\mathrm{Mg}$ and $\mathrm{Si}$, with almost no O. The EDXS composition analysis over the dashed line in Fig. 1 (a) revealed that the particle contained higher $\mathrm{Mg}$ than $\mathrm{Si}$, with negligible $\mathrm{O}$ content. The arrow in Fig. 1 (f) point to high $\mathrm{O}$ content in the Almatrix, which is because of the sample preparation 
technique and is quite common observation, at the edge of a TEM foil.

To understand the origin of corrosion, the TEM specimen was immersed in $0.1 \mathrm{M} \mathrm{NaCl}$ for a short period of $3 \mathrm{~s}$ and the same location as in Fig. $1(\mathrm{a}, \mathrm{b})$ was observed under TEM, and the results are shown in Fig. 1 $\left(a^{\prime}-g^{\prime}\right)$. Arrows in Fig. $1\left(b^{\prime}\right)$ point to the sites at which corrosion occurred. It can be observed that corrosion initiated on the $\mathrm{Mg}_{2} \mathrm{Si}$ particle mostly at the interface of the $\mathrm{Mg}_{2} \mathrm{Si}$ particle and the Al-matrix, revealing that the $\mathrm{Mg}_{2} \mathrm{Si}$ particle is anodic with respect to the Al-matrix (arrows in Fig. 1. $\left(b^{\prime}\right)$ ). In addition, corrosion initiation sites were also observed upon the $\mathrm{Mg}_{2} \mathrm{Si}$ particle away from the $\mathrm{Mg}_{2} \mathrm{Si}$ particle and Al-matrix interface (arrows in Fig. 1. $\left(\mathrm{b}^{\prime}\right)$ ). The $\mathrm{Mg}_{2} \mathrm{Si}$ particle dealloyed by $\mathrm{Mg}$ dissolution and subsequently enriched in $\mathrm{O}$ (arrows in Fig. $1\left(\mathrm{~d}^{\prime}\right.$ and $\left.\mathrm{f}^{\prime}\right)$ ). The chemical composition analysis along the dashed line in Fig. $1\left(a^{\prime}\right)$ clearly revealed the dissolution of $\mathrm{Mg}$ and enrichment of $\mathrm{O}$, with negligible change in $\mathrm{Si}$, at the sites where the $\mathrm{Mg}_{2} \mathrm{Si}$ particle corroded. Further immersion in $0.1 \mathrm{M} \mathrm{NaCl}$ for $30 \mathrm{~s}$ led to complete dissolution of $\mathrm{Mg}$ from the $\mathrm{Mg}_{2} \mathrm{Si}$ particle and the remnant was enriched in $\mathrm{O}$, with negligible change in Si (Fig. $\left.1\left(a^{\prime \prime}-g^{\prime \prime}\right)\right)$. To further investigate the role of the SiO-rich remnant on the corrosion, the TEM foil was further immersed for an extended period of $30 \mathrm{~min}$ in 0.1 $\mathrm{M} \mathrm{NaCl}$. It was revealed that following complete dissolution of $\mathrm{Mg}$ from the $\mathrm{Mg}_{2} \mathrm{Si}$ particle, the $\mathrm{SiO}$-rich remnant became electrochemically inert and did not take part in the corrosion process, as evident from the negligible change in the chemical composition within the dealloyed $\mathrm{Mg}_{2} \mathrm{Si}$ particle and the surrounding Al-matrix, following $30 \mathrm{~s}$ and $30 \mathrm{~min}$ (Fig. $1\left(\mathrm{a}^{\prime \prime}-\mathrm{g}^{\prime \prime}\right)$ and $\left(\mathrm{a}^{\prime \prime \prime}-\mathrm{g}^{\prime \prime \prime}\right)$ ).
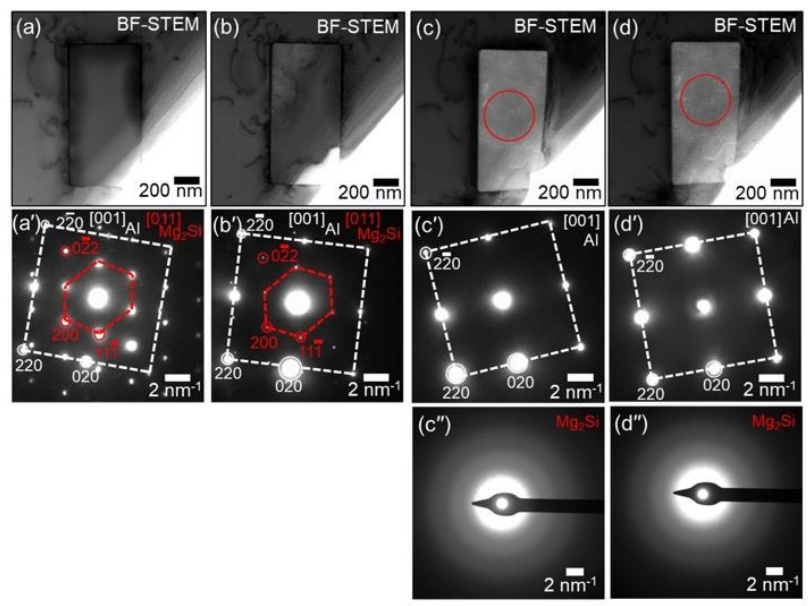

Fig. 2. BF-STEM images of the same $\mathrm{Mg}_{2} \mathrm{Si}$ particle in the Almatrix as shown in Fig. 1, (a) prior to immersion, and following immersion in $0.1 \mathrm{M} \mathrm{NaCl}$ for (b) $3 \mathrm{~s}$, (c) $30 \mathrm{~s}$ and (d) $30 \mathrm{~min}$. (a'$\left.d^{\prime}\right)$ are SADPs corresponding to (a-d), respectively. SADPs in $\left(c^{\prime \prime}\right)$ and $\left(\mathrm{d}^{\prime \prime}\right)$ are collected from the region within the circles in (c) and (d), respectively.

To understand the phase transformation involved with the dealloying of the $\mathrm{Mg}_{2} \mathrm{Si}$ particle following immersion in $0.1 \mathrm{M} \mathrm{NaCl}$, electron diffraction studies were performed on the same $\mathrm{Mg}_{2} \mathrm{Si}$ particle as shown in Fig. 1., prior to and following immersion, and the results are shown in Fig. 2. In the pristine condition, it was revealed that the orientation relationship of the $\mathrm{Mg}_{2} \mathrm{Si}$ particle with the Al-matrix was $[001]_{\mathrm{Al}} / /[011]_{\mathrm{Mg} 2 \mathrm{Si}}$ and $(110)_{\mathrm{Al}} / /$ $(011)_{\mathrm{Mg} 2 \mathrm{Si}}\left(\right.$ Fig. $\left.2\left(\mathrm{a}^{\prime}\right)\right)$. The SADP obtained from Fig. 2 (b), i.e. following $3 \mathrm{~s}$ immersion, did not reveal any significant change in the corrosion-induced phase transformation, i.e. change in the chemistry and/or crystallographic structure, as the extent of corrosion is very small. A significant change in the electron diffraction was observed following complete dealloying of the $\mathrm{Mg}_{2} \mathrm{Si}$ particle, i.e. following $30 \mathrm{~s}$ and $30 \mathrm{~min}$ (Fig. 2). Based on the results, it is quite evident that the crystalline $\mathrm{Mg}_{2} \mathrm{Si}$ particle transformed to amorphous $\mathrm{SiO}$-rich remnant, following dealloying by $\mathrm{Mg}$ dissolution.

Atomic resolution TEM imaging was performed along the $[001]_{\mathrm{Al}} / /[011]_{\mathrm{Mg} 2 \mathrm{Si}}$ direction to understand the onset of corrosion at atomic scale and any influence of the SiOrich remnant on the surrounding Al-matrix, and the results are provided in Fig. 3. Such a resolution is essential because the electron diffraction and chemical composition analysis will not be able to reveal significant details when the extent of corrosion is at the atomic scale. In the pristine condition, clear atomic columns or lattice fringes of the $\mathrm{Mg}_{2} \mathrm{Si}$ particle and the Al-matrix were observed (Fig. 3 (a)). Following immersion for $3 \mathrm{~s}$ (Fig. 3 (b)), the lattice structure within the $\mathrm{Mg}_{2} \mathrm{Si}$ particle transformed to amorphous, which was revealed to be of $\mathrm{SiO}$-rich phase from the chemical composition analysis (Fig. $1\left(\mathrm{a}^{\prime}-\mathrm{g}^{\prime}\right)$ ), and the lattice structure of the Al-matrix did not change. A key finding from the present study is that the corrosion did not initiate uniformly upon the $\mathrm{Mg}_{2} \mathrm{Si}$ particle at its periphery (Fig. 2 and 3 (b)). In fact, corrosion initiated randomly at few of the interfaces of the $\mathrm{Mg}_{2} \mathrm{Si}$ particle and the Al-matrix, and propagated to completely dealloy the $\mathrm{Mg}_{2} \mathrm{Si}$ particle. The direction of corrosion propagation was marked by a single arrowed line in Fig. $3\left(\mathrm{~b}, \mathrm{~b}^{\prime}\right)$. It is evident that with the propagation of corrosion, the crystalline $\mathrm{Mg}_{2} \mathrm{Si}$ structure transforms to amorphous $\mathrm{SiO}$ rich phase (Fig. $3\left(b^{\prime}\right)$ ). Following complete dealloying of the $\mathrm{Mg}_{2} \mathrm{Si}$ particle, i.e., after $30 \mathrm{~s}$ and $30 \mathrm{~min}$ immersion, the lattice structure of the Al-matrix at the interface of the amorphous $\mathrm{SiO}$-rich phase remained unaffected (Fig. 3 (c, $\mathrm{d}$ and $\left.\mathrm{d}^{\prime}\right)$ ), revealing that the SiO-rich remnant became electrochemically inert and did not initiate corrosion in the Al-matrix even at the atomic scale. The electrochemical behaviour of $\mathrm{Mg}_{2} \mathrm{Si}$ in Al-alloys following extended period of exposure to $0.1 \mathrm{M} \mathrm{NaCl}$ at different $\mathrm{pH}$ was provided elsewhere [41]. In that study, it was revealed that the physical dimensions of $\mathrm{Mg}_{2} \mathrm{Si}$ phase decreased following complete dealloying at $\mathrm{pH} 2$, resulting in the formation of a trench at the Al-matrix and SiO-rich phase [41]. However, such significant change in physical dimensions was not observed following complete dealloying of $\mathrm{Mg}_{2} \mathrm{Si}$ phase at $\mathrm{pH} 6$ [41].

The results obtained from the present study aid in understanding the localised corrosion, i.e. pitting and IGC, of Al-alloys associated with $\mathrm{Mg}_{2} \mathrm{Si}$ particles and precipitates. Upon exposure to $\mathrm{NaCl}$, corrosion initiates on $\mathrm{Mg}_{2} \mathrm{Si}$, randomly at the interface of $\mathrm{Mg}_{2} \mathrm{Si}$ and the Almatrix, and also away from the interface (dotted arrows in Fig. 4 (a)). Corrosion propagates to completely dealloy $\mathrm{Mg}_{2} \mathrm{Si}$, leaving amorphous $\mathrm{SiO}$-rich remnant that will become electrochemically inactive. As a result, pitting 

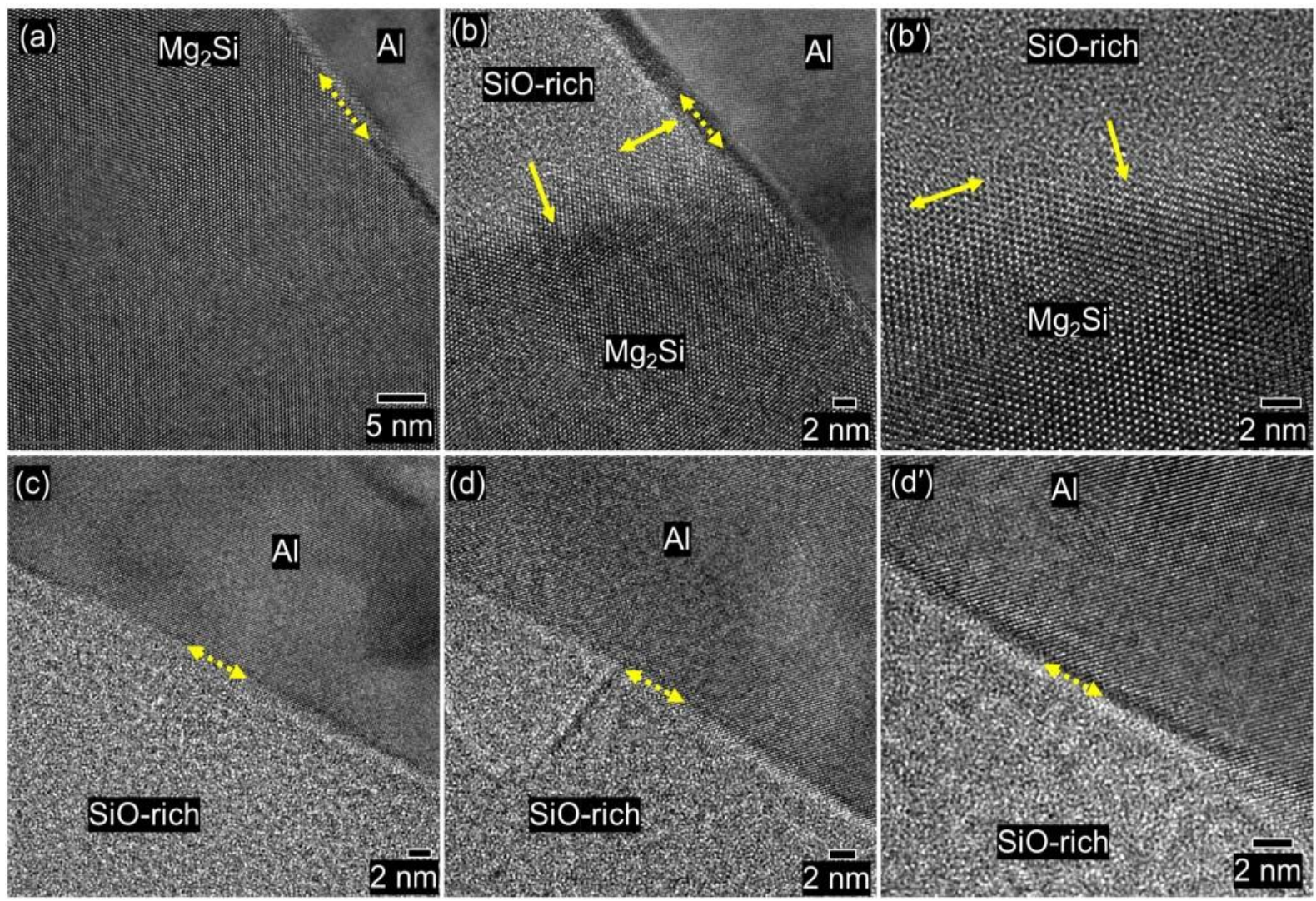

Fig. 3. Atomic resolution TEM images of an identical location showing $\mathrm{Al}$-matrix, $\mathrm{Mg}_{2} \mathrm{Si}$ and the interface between them, (a) prior to immersion, and following immersion in $0.1 \mathrm{M} \mathrm{NaCl}$ for (b) $3 \mathrm{~s}$, (c) $30 \mathrm{~s}$ and (d) $30 \mathrm{~min}$. (b') shows atomic resolution $\mathrm{Mg}_{2} \mathrm{Si}$ following immersion in $0.1 \mathrm{M} \mathrm{NaCl}$ for $3 \mathrm{~s}$. ( $\mathrm{d}^{\prime}$ ) shows higher magnification image of d. Double arrowed dotted lines in (a-d, $\left.d^{\prime}\right)$ and solid lines in ( $b$ and $\left.b^{\prime}\right)$ indicate interfaces between the phases. Whilst single arrowed solid line in (b) and ( $\left.b^{\prime}\right)$ indicate the direction of corrosion propagation.

will not be initiated within the Al-matrix following complete dealloying of $\mathrm{Mg}_{2} \mathrm{Si}$. Of the limited studies to date on IGC, a discrepancy exists in $\mathrm{Cu}$-free alloys [1417, 21-23, 42]. A few studies reported that upon artificial ageing, $\mathrm{Cu}$-free 6xxx Al-alloys suffered IGC as result of the formation of $\mathrm{Mg}_{2} \mathrm{Si}$ precipitates along grain boundaries [14-17, 42]. In contrast, these alloys were also reported to be immune to IGC though $\mathrm{Mg}_{2} \mathrm{Si}$ precipitates form along grain boundaries [21-22]. From the present study, it can be understood that $\mathrm{Mg}_{2} \mathrm{Si}$ precipitates along grain boundaries do not propagate IGC. However, the precipitates rapidly dealloy upon exposure during the IGC process, weakening grain boundaries. As a result, the propensity for IGC of Cu-free 6xxx Al-alloys depends on how closely the $\mathrm{Mg}_{2} \mathrm{Si}$ precipitates are arranged along grain boundaries.
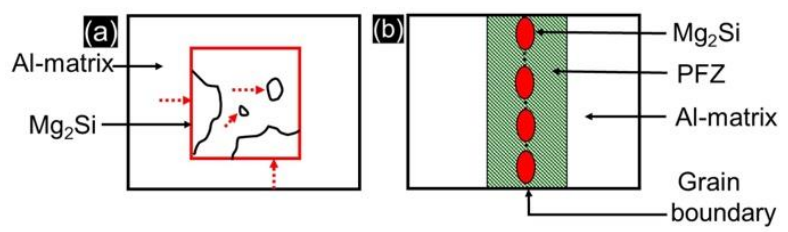

Fig. 4. Schematic microstructural model showing $\mathrm{Mg}_{2} \mathrm{Si}$ (a) within the Al-matrix in a grain and (b) precipitates along a grain boundary. Dotted arrows in (a) point to corrosion initiation sites upon $\mathrm{Mg}_{2} \mathrm{Si}$. PFZ in (b) is a precipitate free zone, which is electrochemically more noble than $\mathrm{Mg}_{2} \mathrm{Si}$ in $0.1 \mathrm{M} \mathrm{NaCl}$ at $\mathrm{pH}$ 6.

\section{Conclusions}

A quasi in-situ TEM method was employed to physically image corrosion initiation and propagation at the atomic to nanometre scale. The corresponding phase transformations (probed via electron diffraction) and chemical composition variations (probed via energy dispersive X-ray spectroscopy) that were associated with the localised corrosion of an $\mathrm{Mg}_{2} \mathrm{Si}$ particle in the Almatrix upon exposure to $0.1 \mathrm{M} \mathrm{NaCl}$ at $\mathrm{pH} 6$ were studied. The following conclusions are drawn:

- Corrosion was initiated upon $\mathrm{Mg}_{2} \mathrm{Si}$ either at its interface with the Al-matrix, but also was observed to initiate away from the interface with the Al-matrix.

- The corrosion process continued until the whole of $\mathrm{Mg}_{2} \mathrm{Si}$ was completely dealloyed by $\mathrm{Mg}$-dissolution, leaving an $\mathrm{SiO}$-rich remnant.

- The SiO-rich remnant was determined herein to be amorphous and electrochemically inactive, and thus it did not take further part in, or initiate further, corrosion in the surrounding Al-matrix - even at the atomic scale.

- The research approach followed herein can be extended to other Al-alloy systems in understanding the corrosion phenomenon at nanometre to atomic scale. 


\section{Acknowledgements}

The authors gratefully acknowledge P. Schumacher and B. Milkereit from University of Rostock, Germany, for the provision of the alloy. Microscopy was performed at the Monash Centre for Electron Microscopy (MCEM).

\section{References}

[1] I.J. Polmear, Light alloys from traditional alloys to nanocrystals, $4^{\text {th }}$ ed. (Oxford, United Kingdom: Elsevier, 2006).

[2] J.F. Nie, "Physical metallurgy in light alloys", in Physical metallurgy, eds. D.E. Laughlin, K. Hono (Elsevier, Amsterdam, 2014).

[3] J.R. Davis, Corrosion of aluminium and aluminium alloys, $1^{\text {st }}$ ed. (Materials Park: ASM International, 1999).

[4] S.K. Kairy, P.A. Rometsch, C.H.J. Davies, N. Birbilis, CORROSION 71, 11 (2015) 1304-1307.

[5] S.K. Kairy, P.A. Rometsch, K. Diao, J.F. Nie, C.H.J. Davies, N. Birbilis, Electrochim. Acta 190 (2016) 92-103.

[6] S.K. Kairy, T. Alam, P.A. Rometsch, C.H.J. Davies, R. Banerjee, N. Birbilis, Metall. Mater. Trans. A 47, 3 (2016) 985-989.

[7] S.K. Kairy, S. Turk, N. Birbilis, A. Shekhter, Corros. Sci. 143 (2018) 414-427.

[8] S.K. Kairy, P.A. Rometsch, C.H.J. Davies, N. Birbilis, CORROSION 73, 1 (2017) 87-99.

[9] J.H. Chen, E. Costan, M.A. Van Huis, Q. Xu, H.W. Zandbergen, Science 312 (2006) 416-419.

[10] D.J. Chakrabarti, D.E. Laughlin, Prog. Mater. Sci. 49 (2004) 389-410.

[11] T. Saito, S. Muraishi, C.D. Marioara, S.J. Andersen, J. Royset, R. Holmestad, Metall. Mater. Trans. A 44 (2013) 4124-4135.

[12] A.K. Gupta, D.J. Lloyd, S.A. Court, Mater. Sci. Eng. A 316 (2001) 11-17.

[13] S.K. Kairy, P.A. Rometsch, C.H.J. Davies, N. Birbilis, CORROSION 73 (2017) 1280-1295.

[14] A. Laurino, E. Andrieu, J.P. Harouard, J. Lacaze, M.C. Lafont, G. Odemer, C. Blanc, J. Electrochem. Soc. 160 (2013) C569-C575.

[15] A. Laurino, E. Andrieu, J.P. Harouard, J. Lacaze, M.C. Lafont, G. Odemer, C. Blanc, ECS Trans. 41 (2012) 93-105.

[16] A. Shi, B.A. Shaw, E. Sikora, CORROSION 61 (2005) 534-547.

[17] A.K. Bhattamishra, K. Lal, Mater. Des. 18 (1997) 2528.

[18] N. Birbilis, R.G. Buchheit, J. Electrochem. Soc. 152, 4 (2005) B140-B151.

[19] R.K. Gupta, N.L. Sukiman, K.M. Fleming, M.A. Gibson, N. Birbilis, ECS Electrochem. Lett. 1, 1 (2012) C1-C3.

[20] K.M. Fleming, A. Zhu, J.R. Scully, CORROSION 68 (2012) 1126-1145.

[21] M.H. Larsen, J.C. Walmsley, O. Lunder, K. Nisancioglu, J. Electrochem. Soc. 157 (2010) C61.

[22] G. Svenningsen, M.H. Larsen, J.H. Nordlien, K. Nisancioglu, Corros. Sci. 48 (2006) 3969-3987.

[23] W.J. Liang, P.A. Rometsch, L.F. Cao, N. Birbilis, Corros. Sci. 76 (2013) 119-128.
[24] J. Wloka, S. Virtanen, J. Electrochem. Soc. 154 (2007) C411-423.

[25] S. Jain, PhD Thesis, The Ohio State University, USA, 2006.

[26] C. Blanc, Y. Roques, G. Mankowski, Corros. Sci. 40 (1998) 1019-1035.

[27] O. Gharbi, N. Birbilis, J. Electrochem. Soc. 165 (2018) C497-C501.

[28] Y.T. Zhou, Y.N. Zan, X.X. Wei, B. Yang, B. Zhang, S.J. Zheng, X.H. Shao, J.H. Dong, X.K. Ma, B.L. Xiao, Q.Z. Wang, Z.Y. Ma, Corros. Sci. 153 (2019) 74-84.

[29] D.M. Sun, Y.M. Jiang, Q.W. Xiang, C. Zhong, J. Gong, L.H. Zhang, J. Li, Mater. Corr. 61 (2010) 105-110. [30] K. Mizuno, A. Nylund, I. Olefjord, Corros. Sci. 43 (2001) 381-396.

[31] O. Knudsen, B.S. Tanem, A. Bjorgum, J. Mardalen, M. Hallenstvet, Corros. Sci. 46 (2004) 2081-2095.

[32] Y. Zhu, K. Sun, G.S. Frankel, J. Electrochem. Soc. 165 (2018) C807-820.

[33] K.A. Yasakau, M.L. Zheludkevich, S.V. Lamaka, M.G.S. Ferreira, Electrochim. Acta 52 (2007) 7651-7659. [34] F. Eckermann, T. Suter, P.J. Uggowitzer, A. Afseth, P. Schmutz, Electrochim. Acta 54 (2008) 844-855.

[35] F. Zeng, Z. Wei, J. Li, X. Tan, Z. Zhang, Z. Zheng, Trans. Nonferrous Met. Soc. China 21 (2011) 2559-2567. [36] Y. Wu, H. Liao, J. Mater. Sci. Technol. 29 (2013) 380-386.

[37] C. Li, J. Sun, Z. Li, Z. Gao, Y. Liu, L. Yu, H. Li, Mater. Charact. 122 (2016) 142-147.

[38] Z. Li, C. Li, Z. Gao, Y. Liu, X. Liu, Q. Guo, L. Yu, H. Li, Mater. Charact. 110 (2015) 170-174.

[39] L.L. Li, B. Zhang, B. Tian, Y. Zhou, J.Q. Wang, E.H. Han, W. Ke, J. Electrochem. Soc. 164 (2017) C240-C249. [40] P. Schumacher, Ph.D. Thesis, University of Rostock, Germany, 2018.

[41] S.K. Kairy, N. Birbilis, CORROSION 76 (2020) 464-475.

[42] S.K. Kairy, P.A. Rometsch, C.H.J. Davies, N. Birbilis, CORROSION 73 (2017) 1280-1295. 